\title{
MANAGING RISKS OF WATER AND SOIL SALINITY ON WATER USE EFFICIENCY
}

\author{
Mahmoud Amer* \\ Water Engineering and Water Structure Engineering Department, Faculty of Engineering, \\ Zagazig University, Egypt \\ Osama Wahed \\ Water Engineering and Water Structure Engineering Department, Faculty of Engineering, \\ Zagazig University, Egypt \\ Hany F. Abd-Elhamid \\ Water Engineering and Water Structure Engineering Department, Faculty of Engineering, \\ Zagazig University, Egypt \\ Civil Engineering Department, College of Engineering, Shaqra University, 11911, Dawadmi, \\ Saudi Arabia

\section{Walaa Y. El-Nashar} \\ Water Engineering and Water Structure Engineering Department, Faculty of Engineering, \\ Zagazig University, Egypt \\ *corresponding author
}

\begin{abstract}
Salinity is a major problem affecting crop production all over the world. About $20 \%$ of cultivated land in the world, and 33\% of irrigated land are salt-affected and degraded, which intensively affects food security. Many researches pointed to its negative impact on yield reduction. Although most previous researches addressed the problem of salinity using stochastic data, they used deterministic methods. This paper aims to use stochastic methods to assess risks of salinity on water use efficiency, and propose strategies to mitigate these risks. Management actions and policies are proposed to manage yield reduction and water use efficiency and mitigate salinity risks. This study expected yield reduction due to major causes of soil salinity. Adopting the suggested strategies could reduce or eliminate the impact of salinity.
\end{abstract}

Keywords: salinity, food security, irrigated land 
Cite this Article: Mahmoud Amer*, Osama Wahed, Hany F. Abd-Elhamid and Walaa Y. El-Nashar, Managing Risks of Water and Soil Salinity on Water Use Efficiency, International Journal of Civil Engineering and Technology, 11(03), 2020, pp.177-191

http://iaeme.com/Home/issue/IJCIET?Volume=11\&Issue $=3$

\section{INTRODUCTION}

Salinity is the presence of soluble salts in soils or waters. Salinity is natural process closely linked with landscape and soil formation processes. However, human activities accelerate salinity processes, contributing long-term land and water degradation. Salinity usually becomes when the concentration of salt or sodium adversely affects plant growth (crops, pastures or native vegetation) or degrades soil structure. It becomes a water issue when the potential use of limited saline water. Salt is derived from the weathering of the earth's crust and is transported and deposited in the landscape by hydrologic mechanisms (rainfall and water movement above and below the terrestrial surface). Salinity processes are also affecting land by agriculture distortion the natural hydrologic equilibrium in a landscape. Salinity is usually developed gradually over an extended period of time. A high salt concentration in soil solution reduces the ability of plants to acquire water, which is referred to as the osmotic or water-deficit effect of salinity. Damage occurs when the concentration is high enough to begin reducing crop growth. The osmotic effect of salinity induces metabolic changes in the plant identical to those caused by water stress-induced "wilting" [Munns, et al., (2002)]. The U.S. Salinity Laboratory in 1943 suggested one of the earliest water quality schemes of classification for irrigated agriculture [Wilcox, (1955)]. Three classes is involved; Class I, Excellent with electrical conductivity less than $1 \mathrm{ds} / \mathrm{m}$ and; Class II, Good to injurious with electrical conductivity 1-3 ds/m; Class III, Injurious to unsatisfactory with electrical conductivity more than $3 \mathrm{ds} / \mathrm{m}$. Ikramov, (2004) studied the soil salinization caused by shallow groundwater table and waterlogging. Ibrakhimov, et al., (2011) analyzed the effects of different groundwater table on soil moisture and salinization and determined optimal ranges of groundwater table so improved drainage system is necessary to control the ground water table. Forkutsa, et al., (2009) indicated that adjusting irrigation timing and mount will be needed to lower groundwater table and reducing salinization. Kahlown and Ashraf, (2005), Cui, et al., (2010) and Soylu, et al., (2014) studied the effect of soil water salinity and groundwater depth on the degree of water and salinity use, the transport characteristics of salinity in soil water and plant growth conditions. Guswa, et al., (2002), Il'Ichev, et al., (2008) and Cui, et al., (2010) indicated that the combined effects of groundwater water level and soil water salinity are more significant in semi-arid and coastal plain regions with shallow groundwater table. Shahid, (2013) indicated that there is no single method to reclaim all types of salt-affected soils; therefore, site specific diagnostics based (salinity, sodicity in depth soil features based) integrated approach (including physical, chemical, hydrological, and biological methods) of soil reclamation is to be adopted for better results. $\underline{\text { Chen, et al., }}$ (2010) studied the effect of trickle irrigation system on salts accumulated in soil profile using two irrigation water salinity. CANADA.DEPARTMENT, (1968) showed that excess water becomes a problem when it interferes with land preparation, plant growth and other farming operations. Surface runoff, deep percolation, evaporation, and transpiration remove a lot of the excess water naturally. When the removal is impeded, either on the surface or in the subsoil, salinity and drainage problems develop and you must then provide artificial drainage. Qadir, et al., (2014) showed that salinity is an issue that will only grow in importance and urgently requires a solution because of a growing human world population and climatic 
changes on a global scale. Ibrakhimov, et al., (2011) stated when the ground water (GW) tables are lowered further to reduce salinization, irrigation timing and amounts will need to be adjusted to meet the changed situation. Maas, (1984) classified the crop tolerance to salts and states the threshold of most important crops. Kurbanbaev and K., (2006) claimed the leaching required to avoid salt accumulation in soil. U.S.Salinity.Laboratory.Staff, (1954) clarified an equation to estimate the water stress caused by soil salinity on crops. Castillo, et al., (2007) studied the effect of soil salinity on osmotic stress and yield reduction for rice as a sensitive crop. Thimmappa, et al., (2015) studied the quantity of gypsum required for reclamation which depends on the amount of exchangeable sodium to be replaced in soil by laboratory tests carried out on the surface soil (0-15 cm). Christen and Ayars, (2001) studied the drainage rate required to control water table to protect the irrigated land. Katschnig, et al., (2013) studied Salicornia as a salt tolerant crop to be irrigated with seawater. Niu, et al., (2012) studied the effect of soil salinity on yield reduction of Jatropha. Shannon, et al., (1999) studied the effect of soil salinity on yield reduction of poplar. Pessarakli, (2016) stated the methods of soil reclamation for different types of salt-affected soil. Novikova, et al., (1981) showed the method of soil leaching using sprinkler irrigation. Vargas, et al., (2018) studied leaching of saline soils by sprinkler irrigation in combination with vertical drainage systems and chemical amelioration treatments.

This study aims to assess soil and water salinity stochastically then evaluate these risks on water use efficiency qualitatively and quantitatively and propose strategies to mitigate these salinity risks.

\section{IMPACT OF SALINITY}

Salinization takes place when the GW with salinity more than $3 \mathrm{gm} / \mathrm{L}$ is $2.0 \mathrm{~m}$ and shallower, and that the GW should not rise above $1.5 \mathrm{~m}$ when salinity less than $3 \mathrm{gm} / \mathrm{L}$. [Kiseliova and Jumaniyazov, (1975)]. At this range of GW levels the actual crop yield nearly reaches the maximum attainable [Dukhovny, (1996)].

Salinity affects crop yield reduction, soil electrical conductivity values and freshwater ecosystem as following:

1. More than 20,000 ha had to be taken out of cultivation due to high level of soil salinity, and the loss is estimated at a total of 30,000 tons of cotton per year. [FAO, (1971)]

2. The yield decreased by $50 \%$ in about 30,000 ha, and the total loss is estimated at 20,000 tons of cotton per year. [FAO, (1971)]

3 . The yield decreased by $20 \%$ in about 60,000 ha, and the total loss is estimated at about 18,000 tons of cotton per year. [FAO, (1971)]

4. Soil electrical conductivity (ECs) values increased with increasing salinity of irrigation water and decreased soil moisture depletion in calcareous soil [Ragab, (2000)]. Total soil salinity increased from 1.87 to $24.83 \mathrm{ds} / \mathrm{m}$ with increasing irrigation salinity from 0.58 to $3.67 \mathrm{ds} / \mathrm{m}$ [Ragab, (2000)]

5. Its considered about $20-50 \%$ of the freshwater bodies in cultivated areas could be salt affected owing to irrigation [Pitman and Läuchli, (2002)]

6. Fresh water ecosystem is threated by soil salinization as salt free rainwater converts to highly saline after exposure to even moderate or high soil salinity levels in form of run off pollutants fresh-water systems [Neave and Rayburg, (2006)].

7. Freshwater applications needed to be nearly doubled to cope with salinization [Kurbanbaev and K., (2006)]. 
8. The effect of soil salinity on osmotic stress and yield reduction for rice using electrical conductivity (EC) was adjusted to $6 \mathrm{ds} / \mathrm{m}$ and $12 \mathrm{ds} / \mathrm{m}$ and yield reduction $40.5-71.9 \%$ [Castillo, et al., (2007)].

\section{METHODOLOGY}

Risk management methodology is used to achieve the study objectives. The methodology includes:

i. Identification: Identify source of salinity risk

ii. Assessment: Assess salinity risks in terms of its impact and probability of occurrence by:

a. Qualitative analysis using Delphi Technique.

b. Quantitatively analysis using expected value (EV).

c. Using sensitivity analysis to study the risk change on water use efficiency (Eu).

iii. Mitigation: Develop a strategy to reduce and manage possible damage.

OSPMI, (2007), El-Nashar and Elyamany, (2017) defined the risk as an uncertain condition or event that has a negative or a positive effect on at least one of project objectives, such as quality, cost or time. Risk is a combination of magnitude of consequences of the occurrence and probability of the occurrence of a defined hazard. Managing risks is an integral part of good fundamental and management of achieving good effective procurement and business of goods and services. The aims of risk management are to minimize the risks of partially achieving objectives and take the advantage of opportunities; facilitate better business; provide insight, confidence and knowledge for better decision making; reduce overall risk exposure; and increase certainty.

\subsection{Identification: Identify Source of Risk}

Risk identification has an important effect on the following stages so it's considered as a critical stage. Without taking all risks into consideration, the missed risks will not be evaluated and managed. The outcome of risk identification is a list of risks. Diagramming Cause-and-effect is a technique used to identify risks. Cause-and-effect (fishbone) diagrams show the relationship between the effects of problems and their causes as shown in Figure 1. This diagram shows every potential cause-and-effect of a problem and the effect that each proposed solution could have on the problem. From this diagram, the list of salinity risks is made.

The list of risks resulted from the "cause-and-effect" diagram consists of the following:

1. Effect of water table rise on increasing soil salinity

2. Effect of irrigation system on soil salinity

3. Effect of poor drainage system on soil salinity 


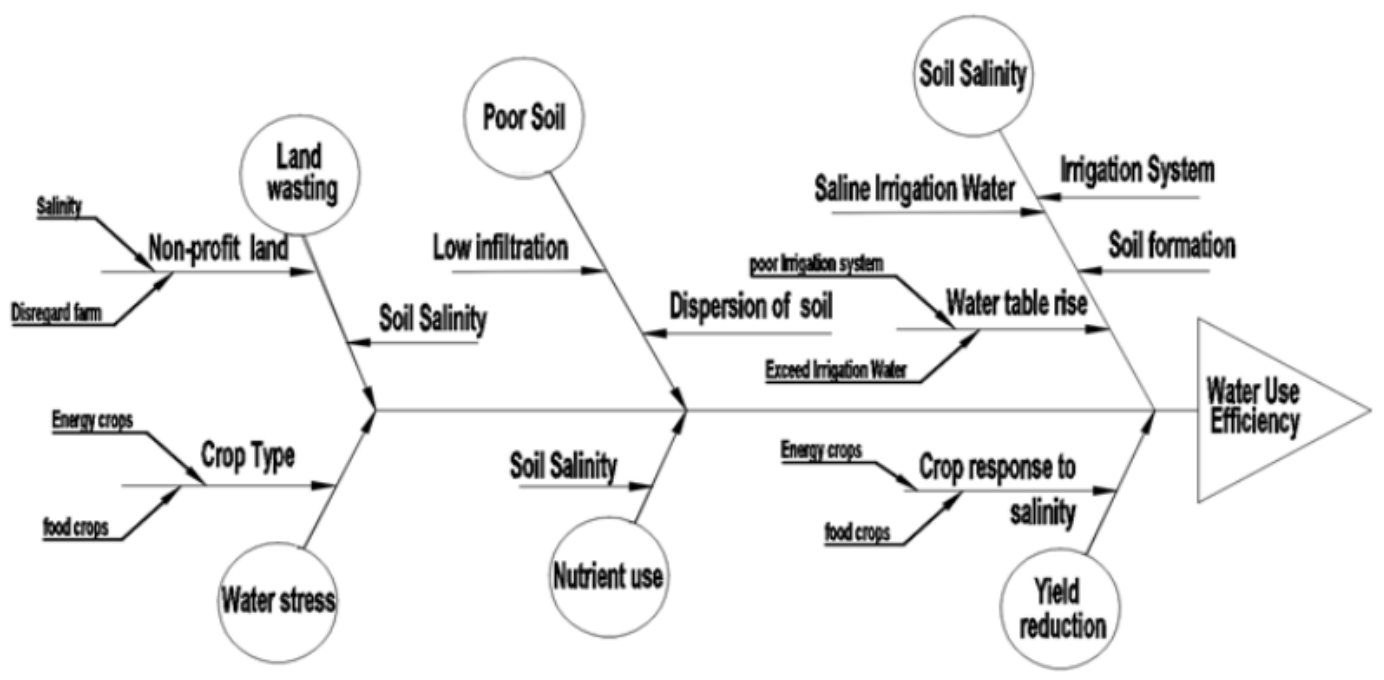

Figure 1: Cause and Effect Diagram

1. Effect of saline irrigation water on soil salinity

2. Effect of formation of soil on increasing soil salinity

3. Yield reduction of energy crops under effect of salinity

4. Yield reduction of sensitive crops under effect of salinity

5. Yield reduction of moderate crops under effect of salinity

6. Yield reduction of tolerant crops under effect of salinity

7. Salinity effect on reduction infiltration rate of soil

8. Salinity effect on dispersion of fine soil

9. Salinity problems with infrastructure such as irrigation and drainage pipes

10. Value of water use under effect of salinity

11. Quantity of water use under effect of salinity

12. Effect of salinity on increasing water stress for sensitive crops to drought

13. Effect of salinity on increasing water stress for moderate crops to drought

14. Effect of salinity on increasing water stress for tolerant crops to drought

15. Effect of salinity on increasing water stress for energy crops

16. Salinity effect on declining population of rural communities

17. Salinity effect on loss of business (both existing and potential)

18. Value of nutrient use under effect of salinity

19. Quantity of nutrient use under effect of salinity

20. Salinity effect on increasing run off

\subsection{Risk Assessment}

Assessing risks in terms of probability of occurrence and severity of impact is the next step after identification of risks. Risks arising from the soil salinity are assessed by determining the probability of occurrence of each risk and the impact of that risk, if occurred. Risk assessment passes through three stages:

a) Qualitative risk analysis.

b) Quantitative risk analysis. 
c) Sensitivity analysis.

\subsubsection{Qualitative Risk Analysis}

After identifying risks, the risk magnitude shall be provided by qualitative risk analysis "subjectively" based on risk probability and impact of occurrence. Delphi Technique is used to determine the impact and probability of risks using expert's opinions [ $\underline{\mathrm{Hsu} \text { and Sandford, }}$ (2007)]. Participants in Delphi Technique aren't gathered in the same place while generating and rating ideas. In this study, identified risks are ranked by Delphi Technique using a questionnaire sent to 40 experts. The probability and impact of soil salinity is rated by experts by using questionnaires. 31 experts responded to the questionnaire with a response rate of $77.5 \%$. Table 1 shows the used questionnaire.

Two stages are considered in Delphi Technique. In the first stage the impact and probability of each risk either as; very low, low, moderate, high or very high are assessed by asking the experts as shown in Table 1. The average probability and impact of each risk are calculated after collecting all responses as shown in Table 2. As shown in Table 2, Column (1) and (2) shows the average probability $\left(\mathrm{P}_{\mathrm{av}}\right)$ and average impact $\left(\mathrm{I}_{\mathrm{av}}\right)$ of each risk based on responses collected from focus group. In table 2 Column (3) shows the score of each risk $\left(\mathrm{R}_{\mathrm{s}}\right)$. Column (4) shows the category of risks $\left(\mathrm{R}_{\mathrm{C}}\right)$ according to its score. These categories are classified from 1 to 5 , where category 1 is assigned to very low and category 5 is assigned to very high risks as shown in Table 3 . These categories are determined by the focus group ( 31 experts) by sending the average probability and average impact of each risk to them.

Table 1: A Questionnaire for Soil Salinity Risks

\begin{tabular}{|c|c|c|c|c|c|c|c|c|c|c|c|}
\hline \multirow[b]{2}{*}{$\begin{array}{c}\text { RIS } \\
\text { K } \\
\text { CO } \\
\text { DE }\end{array}$} & \multirow[b]{2}{*}{ RISK } & \multicolumn{5}{|c|}{ PROBABILITY } & \multicolumn{5}{|c|}{ IMPACT } \\
\hline & & $\begin{array}{l}\mathrm{V} \\
\text { er } \\
\mathrm{y} \\
\text { lo } \\
\mathrm{w}\end{array}$ & $\begin{array}{l}\text { Lo } \\
\mathrm{w}\end{array}$ & $\begin{array}{l}\text { Moder } \\
\text { ate }\end{array}$ & $\begin{array}{l}\mathrm{Hig} \\
\mathrm{h}\end{array}$ & $\begin{array}{c}\text { Ver } \\
\mathrm{y} \\
\text { high }\end{array}$ & $\begin{array}{c}\text { Ver } \\
\text { y } \\
\text { low }\end{array}$ & Low & $\begin{array}{l}\text { Moderat } \\
\mathrm{e}\end{array}$ & $\begin{array}{c}\mathrm{Hig} \\
\mathrm{h}\end{array}$ & $\begin{array}{c}\text { Ver } \\
\text { y } \\
\text { hig } \\
\text { h }\end{array}$ \\
\hline P1 & $\begin{array}{c}\text { Effect of water table lowering on } \\
\text { soil salinity }\end{array}$ & & & & & & & & & & \\
\hline $\mathbf{P 2}$ & $\begin{array}{c}\text { Effect of modern irrigation system } \\
\text { on soil salinity }\end{array}$ & & & & & & & & & & \\
\hline P3 & $\begin{array}{c}\text { Effect of poor drainage system on } \\
\text { soil salinity }\end{array}$ & & & & & & & & & & \\
\hline P4 & $\begin{array}{c}\text { Effect of saline irrigation water on } \\
\text { soil salinity }\end{array}$ & & & & & & & & & & \\
\hline P5 & $\begin{array}{l}\text { Effect of formation of soil on } \\
\text { increasing soil salinity }\end{array}$ & & & & & & & & & & \\
\hline P6 & $\begin{array}{l}\text { Yield reduction of energy crops } \\
\text { under effect of salinity }\end{array}$ & & & & & & & & & & \\
\hline P7 & $\begin{array}{l}\text { Yield reduction of sensitive crops } \\
\text { under effect of salinity }\end{array}$ & & & & & & & & & & \\
\hline P8 & $\begin{array}{l}\text { Yield reduction of moderate crops } \\
\text { under effect of salinity }\end{array}$ & & & & & & & & & & \\
\hline P9 & $\begin{array}{l}\text { Yield reduction of tolerant crops } \\
\text { under effect of salinity }\end{array}$ & & & & & & & & & & \\
\hline P10 & $\begin{array}{l}\text { Salinity effect on reduction } \\
\text { infiltration rate of soil }\end{array}$ & & & & & & & & & & \\
\hline P11 & Salinity effect on dispersion of fine & & & & & & & & & & \\
\hline
\end{tabular}




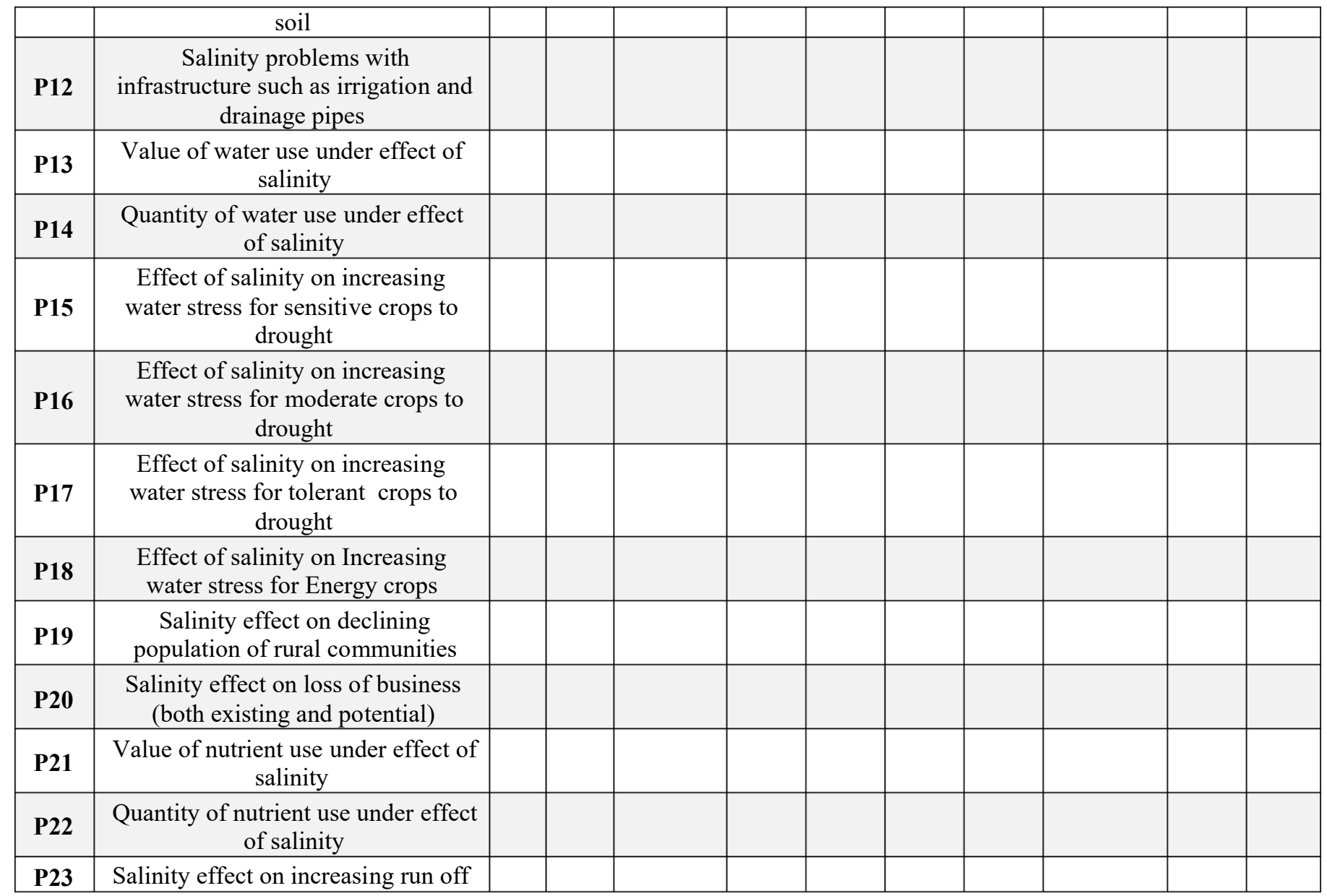

Table 2: Matrix of Risk Probability and Impact

\begin{tabular}{|c|c|c|c|c|}
\hline Risk code & $\mathbf{P}_{\mathbf{a v}} \mathbf{( 1 )}$ & $\mathbf{I}_{\mathbf{a v}} \mathbf{( 2 )}$ & $\mathbf{R}_{\mathbf{S}} \mathbf{( 3 )}$ & $\mathbf{R}_{\mathbf{C}} \mathbf{( 4 )}$ \\
\hline P1 & 4.2 & 4.5 & 18.5 & 4 \\
\hline P2 & 3.0 & 3.7 & 10.9 & 3 \\
\hline P3 & 3.0 & 3.7 & 11.0 & 3 \\
\hline P4 & 1.9 & 2.9 & 5.7 & 2 \\
\hline P5 & 1.8 & 2.7 & 5.0 & 1 \\
\hline P6 & 2.0 & 2.2 & 4.5 & 1 \\
\hline P7 & 3.9 & 3.7 & 14.6 & 3 \\
\hline P8 & 2.9 & 3.5 & 10.4 & 3 \\
\hline P9 & 2.0 & 2.0 & 4.1 & 1 \\
\hline P10 & 2.5 & 2.4 & 5.9 & 1 \\
\hline P11 & 1.8 & 1.3 & 2.3 & 1 \\
\hline P12 & 1.9 & 2.2 & 4.1 & 2 \\
\hline P13 & 3.0 & 3.0 & 8.9 & 3 \\
\hline P14 & 3.2 & 3.1 & 10.1 & 4 \\
\hline P15 & 4.0 & 4.0 & 16.1 & 2 \\
\hline P16 & 2.1 & 3.0 & 6.3 & 1 \\
\hline P17 & 1.6 & 2.1 & 3.4 & 1 \\
\hline P18 & 1.4 & 1.2 & 1.6 & \\
\hline
\end{tabular}




\begin{tabular}{|l|l|l|l|l|}
\hline P19 & 2.8 & 3.5 & 10.0 & 2 \\
\hline P20 & 1.5 & 2.7 & 4.0 & 1 \\
\hline P21 & 1.9 & 2.8 & 5.2 & 2 \\
\hline P22 & 1.9 & 2.9 & 5.6 & 2 \\
\hline P23 & 1.5 & 1.4 & 2.1 & 1 \\
\hline
\end{tabular}

Table 3: Risk Category according to Score

\begin{tabular}{|c|c|c|c|c|c|}
\hline Category & 1 & 2 & 3 & 4 & 5 \\
\hline Risk score & $(1-5)$ & $>(5-10)$ & $>(10-15)$ & $>(15-20)$ & $>(20-25)$ \\
\hline
\end{tabular}

\subsubsection{Quantitative Risk Analysis}

After finalizing qualitative risk analysis quantitative risk analysis is carried out. Risks are prioritized and ranked based on its effect on water use efficiency. Quantitative risk analysis utilized expected value (EV) Analysis which determined the "Risk Magnitude" [OSPMI, (2007)]. EV equals the product of the risk probability as a ratio (P\%) and the risk impact (I). Risks of Categories 3 and 4 are selected initially for quantitative risk analysis. These risks are (P1, P2, P3, P7, P8, P14, P15, and P19) as shown in Table2

Table 4: Expected Value (EV)

\begin{tabular}{|c|c|c|c|c|}
\hline Risk code & $\mathbf{R}_{\mathbf{C}}$ & $\mathbf{P}(\mathbf{\%})$ & $\mathbf{I}$ & $\mathbf{E V}=\mathbf{P} \mathbf{x} \mathbf{~}$ \\
\hline $\mathbf{1}$ & 4 & 84 & $72.4-79.8 \%$ & $60.8-67 \%$ \\
\hline $\mathbf{2}$ & 3 & 60 & $46-115 \%$ & $27.6-69 \%$ \\
\hline $\mathbf{3}$ & 3 & 60 & $37.2-41.6 \%$ & $22.32-25 \%$ \\
\hline $\mathbf{7}$ & 3 & 78 & $14-33 \%$ & $10.92-25.74 \%$ \\
\hline $\mathbf{8}$ & 3 & 58 & $4-20 \%$ & $2.32-11.6 \%$ \\
\hline $\mathbf{1 4}$ & 3 & 64 & $100 \%$ & $64 \%$ \\
\hline $\mathbf{1 5}$ & 4 & 80 & $40.5-71.9 \%$ & $32.4-57.52 \%$ \\
\hline
\end{tabular}

\subsubsection{Quantitative Analysis of P1}

P1 refers to "effect of water table lowering on soil salinity". For lowering water table to $25 \%$ and $50 \%$ from critical case at $1.2 \mathrm{~m}$ from soil surface, the salinity of soil decreased by $72.4 \%$, and $79.8 \%$ respectively. [Xia, et al., (2016)]. For that decrease in soil salinity, soil leaching will decrease. EV is calculated by multiplying the probability of risk occurrence and its impact. The risk probability is converted to percentage as shown in Table 4 from scale 1-5, as presented in Table 2. For example, the average probability of P1 is 4.2 on a scale $1-5$ and it is converted into $84 \%$. As shown in Table 2, the impact and the EV of P1 (decrease in soil salinity) equals $60.8-67 \%$ from controlled soil salinity.

\subsubsection{Quantitative Analysis of $P 2$}

P2 refers to "effect of modern irrigation system on soil salinity". Using modern irrigation method as trickle irrigation system salts accumulate gradually in the soil profile increased to $46 \%$ and $115 \%$ at the end of $1^{\text {st }}$ crop season under the moderate saline water irrigation (E.C $=$ $3.6 \mathrm{ds} / \mathrm{m}$ ) and high saline water irrigation (E.C $=6.7 \mathrm{ds} / \mathrm{m}$ ) respectively. [Chen, et al., $(2010)]$. This salinity increasing leads to increase soil leaching by $46-115 \%$. As shown in Table 4 , the average probability of $\mathrm{P} 2$ is $60 \%$ then the impact is increasing soil salinity by $27.6-69 \%$ for irrigation salinity (3.6 to $6.7 \mathrm{ds} / \mathrm{m}$ ). 


\subsubsection{Quantitative Analysis of $P 3$}

P3 refers to "effect of poor drainage system on soil salinity". By using poor drainage system the water table will rise and cause increasing salinity of the soil as P1. With shallow water table $0.3 \mathrm{~m}$ the salinity of the $20 \mathrm{~cm}$ soil layer increased by $41.6 \%$ relative to the salinity of the control soils, and with water table $0.6 \mathrm{~m}$ the salinity of the $50 \mathrm{~cm}$ soil layer salinity increased by $37.2 \%$ relative to the salinity of the control soils [Xia J., et al., 2016]. As shown in Table 4, the average probability of $\mathrm{P} 3$ is $60 \%$, the impact of increasing soil salinity is 37.2 $-41.6 \%$ and the EV of increasing salinity is $22.32-25 \%$.

\subsubsection{Quantitative Analysis of P7}

P7 refers to "yield reduction of sensitive crops under effect of salinity". Sensitive crops are severely affected by salinity more than other crops where the yield is reduced by $14-33 \%$ per one $\mathrm{ds} / \mathrm{m}$ and maximum soil salinity without yield loss threshold ranged from $1-1.8 \mathrm{ds} / \mathrm{m}$ [Maas, (1984)]. As shown in Table 4, the average probability of P7 is $78 \%$, the impact is decreasing yield of sensitive crops by $14-33 \%$ and EV of yield reduction of sensitive crops under effect of salinity is $10.92-25.74 \%$ if the soil salinity increased by $1 \mathrm{ds} / \mathrm{m}$ more than threshold.

\subsubsection{Quantitative Analysis of $P 8$}

P8 refers to "yield reduction of moderate crops under effect of salinity". Salt moderate crops are affected by salinity less than salt tolerant crops where the yield is reduced by $4-20 \%$ per one $\mathrm{ds} / \mathrm{m}$ and maximum soil salinity without yield loss (threshold) ranged from $2.7-6.8 \mathrm{ds} / \mathrm{m}$ [Maas, (1984)]. As shown in Table 4, the average probability of P8 is $58 \%$, the impact is decreasing yield of sensitive crops by $4-20 \%$ and the EV of yield reduction of moderate crops under effect of salinity is $2.32-11.6 \%$ if the soil salinity increased by $1 \mathrm{ds} / \mathrm{m}$ more than threshold.

\subsubsection{Quantitative Analysis of P14}

P14 refers to "quantity of water use under effect of salinity". Freshwater applications needed to be nearly doubled (increase to $100 \%$ ), to cope with salinization [Kurbanbaev and K., (2006)]. As shown in Table 4, the average probability of P14 is $64 \%$, the impact is doubling volume of irrigation water, and the $\mathrm{EV}$ of increasing quantity of irrigation water due to salinity is $64 \%$ of the volume of irrigation water for non-saline soil.

\subsubsection{Quantitative Analysis of P15}

P15 refers to "effect of salinity on increasing water stress for sensitive crops to drought". For rice (as a sensitive crops), yield reduction caused by osmotic stress was measured by doubling electrical conductivity $(\mathrm{EC})$ of the sodium chloride $(\mathrm{NaCl})$ solution which caused yield reduction $40.5-71.9 \%$ that's lead to decreasing water use efficiency by $40.5-71.9 \%$. The relationship between the osmotic potential (Us) and salinity electric conductivity (EC) as: Us $($ bar $)=-0.36 \mathrm{EC}(\mathrm{ds} / \mathrm{m})$ [U.S.Salinity.Laboratory.Staff, (1954)]. As shown in Table 4, the average probability of $\mathrm{P} 15$ is $80 \%$, the impact is $40-71.9 \%$, and the EV of effect of salinity on increasing water stress for sensitive crops to drought due to increasing soil salinity and osmotic pressure is $32.4-57.52 \%$.

Water Use Efficiency (Eu)

Water use efficiency $(\mathrm{Eu})$ is the ratio between effective water use and actual water withdrawal. It characterizes how to use water effectively. [FAO, (2017)] 
The effect of previous risks on Eu after application of EV is as:

1. Effect of P1: For lowering water table to $25 \%$ and $50 \%$ from critical case, the soil salinity will decrease by $60.8-67 \%$ respectively, this leads to decrease the soil leaching and increase Eu by $60.8-67 \%$.

2. Effect of P2: For using a trickle irrigation system as modern irrigation system, the soil salinity will increase by $27.6-69 \%$. This leads to increase of leaching water and decrease Eu by 27.6 - 69\%.

3. Effect of P3: using poor drainage system, soil salinity will increase by 37.2 $41.6 \%$, then soil leaching will increase and Eu will decrease by $22.32-25 \%$.

4. Effect of P7: The yield reduction of sensitive crops will reduce salinity by 14 $33 \%$ per one ds/m which means decreasing Eu by $10.92-25.74 \%$.

5. Effect of P8: The yield reduction of moderate crops will decrease salinity by 4 $20 \%$ per one $\mathrm{ds} / \mathrm{m}$ which means decreasing Eu by $2.32-11.6 \%$.

6. Effect of P14: The quantity of fresh water use will be doubled under effect of salinity that leads to decrease Eu by $28 \%$.

7. Effect of P15: Increasing water stress for sensitive crops due to $\mathrm{NaCl}$ salts leads to decrease yield reduction by $40.5-71.9 \%$ that leads to decrease Eu by $32.4-57.52 \%$.

\subsubsection{Sensitivity Analysis (SA)}

Sensitivity analysis SA is a technique of risk analysis which provides answer of "what if" questions. SA is widely used due to its ability to focus on particular estimates and simplicity. [OSPMI, (2007)]. In this paper SA is used to identify the impact of a change in each risk on water use efficiency. Spider diagram (Figure 2) is drawn to show that.

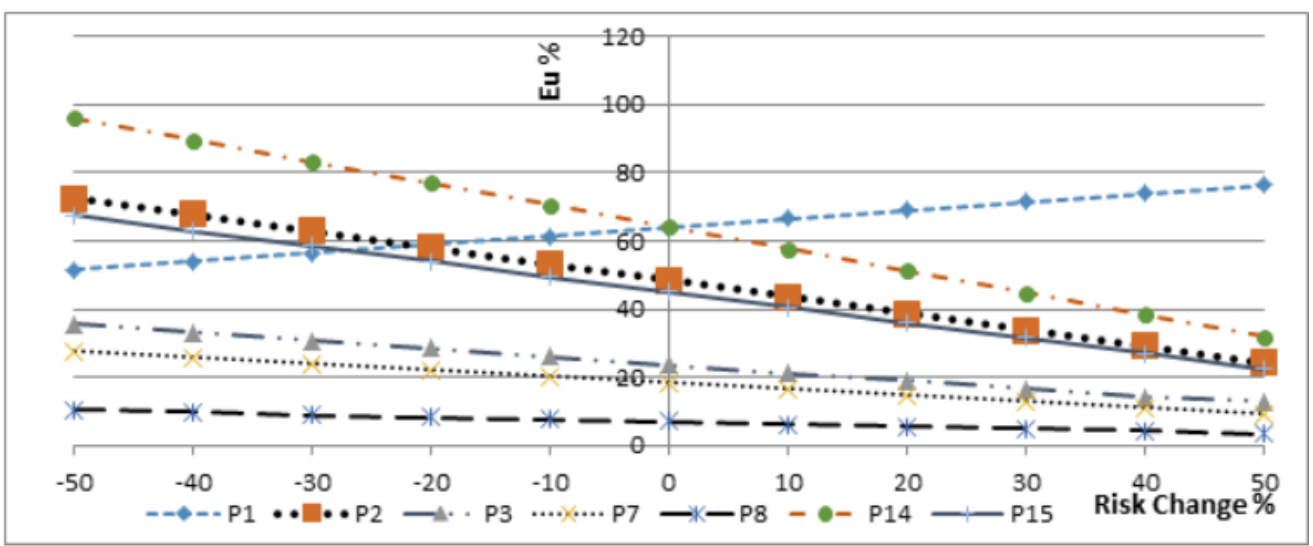

Figure (2): Spider Diagram for Risks Effects on Eu

From the figure it is found that the change of lowering water table (P1) from $-50 \%$ to $50 \%$ leads to a change in Eu from $51.5 \%$ to $76.3 \%$ respectively, the change of salinity of irrigation water in the trickle irrigation system (P2) from $-50 \%$ to $50 \%$ leads to a change in Eu from $72.45 \%$ to $24.15 \%$ respectively, the change of using poor drainage system (P3) from $-50 \%$ to $50 \%$ leads to a change in Eu from $35.49 \%$ to $13.013 \%$ respectively, the change of the yield reduction of sensitive crops (P7) from $-50 \%$ to $50 \%$ leads to a change in Eu from $27.495 \%$ to $9.165 \%$ respectively, the change of the yield reduction of moderate crops (P8) from $-50 \%$ to $50 \%$ leads to a change in $\mathrm{Eu}$ from $10.44 \%$ to $3.48 \%$ respectively, the change in used fresh water quantity (P14) from $-50 \%$ to $50 \%$ leads to a change in Eu from $96 \%$ to $32 \%$ 
respectively and the change of increasing water stress for sensitive crops due to $\mathrm{NaCl}$ salts (P15) from $-50 \%$ to $50 \%$ leads to a change in Eu from $67.44 \%$ to $22.48 \%$ respectively.

\subsection{Mitigation of Risks}

Management of water use efficiency requires to minimize irrigation water and maximize crop yield as water use efficiency is the ratio of total biomass or grain yield to water supply or evapotranspiration or transpiration on a daily or seasonal basis [Sinclair, et al., (1984)]. All of the studied risks lead to reduction in yield so a number of management actions should be used to prevent this reduction in yield. The following list of management actions and strategies are suggested to mitigate risks of reducing water use efficiency:

1) Install and improve existing drainage system to control very shallow water-tables (less than $1 \mathrm{~m}$ ) that resulted mostly after irrigation but also after rainfall. It's necessary for cropping systems or whether lower water-table control criteria (water tables depths more than $1.2 \mathrm{~m}$ ) would be adequate to protect these areas [Christen and Ayars, (2001)].

2) Planting salt-tolerant crops in saline agriculture to adapt with the salinity increasing [Safdar, et al., (2019)]. A few vegetable crops can be irrigated with seawater, with a $\mathrm{NaCl}$ concentration of about $50 \mathrm{ds} / \mathrm{m}$. [Katschnig, et al., (2013)]. For using soil salinity $7.7 \mathrm{ds} / \mathrm{m}$ the yield production of barley, cotton, sorghum, wheat is $100 \%-100 \%-85.6 \%-87.93 \%$ respectively [Maas, (1984)]

3) Planting energy crops in saline soil with high salinity levels and heavy metals contained[Yadav, et al., (2019)]. Energy crops may be a suitable alternative to use saline land without reclamation. Energy crops like Jojuba (50\% of yield reduction occurs at $15 \mathrm{ds} / \mathrm{m}$ [Egyptian Gulf Land Reclamation]), Jatropha (50\% of yield reduction occurs at $9 \mathrm{ds} / \mathrm{m}$ [Niu, et al., (2012)]), Miscanthus (50\% of yield reduction occurs at $10.65 \mathrm{ds} / \mathrm{m}$ [O'Loughlin, et al., (2017)]), Poplar ( $15 \%$ of yield reduction occurs at $7.6 \mathrm{ds} / \mathrm{m}$ [Shannon, et al., (1999)]).

4) Soil leaching: flooding is the main technique of soil leaching. Preparation for leaching includes defining types of salts affected soil to choice the method of reclamation [Pessarakli, (1994)]:

For Sodium chloride and sulfate which happened in Arid and semiarid causing high osmotic pressure of soil solution, toxic effect of chlorides amount of water needed to be add to leach the soil.

For Sodium ions capable of alkaline hydrolysis which occurred in semiarid, semi-humid and humid causing high PH (alkali) and poor water physical conditions PH must be lowered or neutralized by chemical amendments.

For magnesium ions which occured in semiarid and semi-humid causing toxic effect, high osmotic pressure, Calcium deficiency chemical amendments must be added and then leaching.

For Calcium ions (mainly $\mathrm{CaSo}_{4}$ ) which occured in semiarid and arid causing low $\mathrm{PH}$ (acidic) toxic effect, alkaline amendments must be added.

1) Leaching of saline soils by sprinkler irrigation in combination with vertical drainage systems and chemical amelioration treatments are 10 times cheaper and require 4-5 times less water, than traditional leaching by flooding. The rates of soil desalinization and yield increases are the same in both cases [Vargas, et al., (2018)]. 
2) Land reclamation which depends on the quantity of gypsum required for reclamation and the amount of exchangeable sodium to be replaced in the soil. The total investment required to reclaim one hectare sodic land was varied between (10,000 LE) in 'slight' sodic category land to12,000 LE) in 'severe' sodic category land. If there are no canal or tube-well irrigation facilities, an additional amount of $(5,500 \mathrm{LE})$ per hectare investment on tube-well is required to create irrigation facility. [Thimmappa, et al., (2015)].

\section{RESULTS AND DISCUSSION}

The results showed that, EV for lowering water table is decreasing salinity by $60.8-67 \%$ and change for this risk from $-50 \%$ to $50 \%$ leads to Eu changing from $51.5 \%$ to $76.3 \%$, EV for using trickle irrigation system with different is increasing in soil salinity by $27.6-69 \%$ and change for this risk from $-50 \%$ to $50 \%$ leads to Eu changing from $72.45 \%$ to $24.15 \%$, EV for using poor drainage is increasing soil salinity by $22.32-25 \%$ and change for this risk from $50 \%$ to $50 \%$ leads to Eu changing from $35.49 \%$ to $13.013 \%$, Ev for yield reduction of sensitive crops by salinity is $10.92-25.74 \%$ and change for this risk from $-50 \%$ to $50 \%$ leads to Eu changing from $27.495 \%$ to $9.165 \%$, Ev for yield reduction of moderate crops by salinity is $2.32-11.6 \%$ and change for this risk from $-50 \%$ to $50 \%$ leads to Eu changing from $10.44 \%$ to $3.48 \%$, EV for quantity of used fresh water under effect of salinity is $64 \%$ and change for this risk from $-50 \%$ to $50 \%$ leads to Eu changing from $96 \%$ to $32 \%$, EV for increasing water stress for sensitive crops under effect of salinity is $32.4-57.52 \%$ and change for this risk from $-50 \%$ to $50 \%$ leads to Eu changing from $67.44 \%$ to $22.48 \%$.

\section{CONCLUSION}

Salinity is the major problem affecting irrigated lands, which directly affects food security and water use around the world. This paper assessed the risks of soil salinity and evaluated these risks qualitatively and quantitatively and put some strategies to mitigate these risks by applying new methodology of risk management including an identification the reasons of salinity and its effect by cause-effect diagram to study the risk of water and soil salinity on water use efficiency. Risk assessment passes through three stages: i. Qualitative risk analysis by Delphi technique to determine the probability and impact of risks, ii. Quantitative risk analysis to determine the "Risk Magnitude", this analysis is done by using Expected Value. iii. Sensitivity analysis to study the risk change on water use efficiency. Management actions and strategies are proposed to mitigate risks of salinity to increase crop yield and reduce water consumption. Soil salinization is closely linked to the use of in-efficient cropping systems (i.e., choices of crop, crop rotation, tillage practice, irrigation, and nutrient and pest management applied on a particular field over a particular period). The results showed that improve soil properties is the most efficient method to increase water use efficiency and increase yield by using efficient quantity of water, having suitable water table level, suitable irrigation system and suitable drainage system respectively then suitable crop pattern. Most strategies and management actions require time to be implemented as planting salt-tolerant crops and energy crops in saline agriculture to adapt the salinity increasing and soil improvement which is necessary to break the negative spiral of degradation, increased costs, increased inputs and environment damage. 


\section{REFRENCES}

[1] Canada.Department, (1968) "CANADA DEPARTMENT OF AGRICULTURE Publication 1314 1968"

[2] Castillo, E. G., Tuong, T. P., Ismail, A. M. and Inubushi, K., (2007) "Response to salinity in rice: Comparative effects of osmotic and ionic stresses" Plant Production Science 10:2 $159-170$

[3] Chen, W., Hou, Z., Wu, L., Liang, Y. and Wei, C., (2010) "Evaluating salinity distribution in soil irrigated with saline water in arid regions of northwest China" Agricultural water management 97:12 2001-2008

[4] Christen, E. W. and Ayars, J. E., (2001) "Subsurface drainage system design and management in irrigated agriculture: Best management practices for reducing drainage volume and salt load"

[5] Cui, B., Yang, Q., Zhang, K., Zhao, X. and You, Z., (2010) "Responses of saltcedar (Tamarix chinensis) to water table depth and soil salinity in the Yellow River Delta, China" Plant Ecology 209:2 279-290

[6] Dukhovny, V. A., (1996) "Drainage development in the arid zones of Central Asia. In: Bos, M.G. (Ed.), The Interrelation Between Irrigation, Drainage and the Environment. Proceedings, NATO Advanced Research Workshop on Drainage and Development in Arid Zones. Kluwer Academic Pub., Dordrecht, the etherlands" 45-55

[7] El-Nashar, W. Y. and Elyamany, A. H., (2017) "Managing risks of the Grand Ethiopian Renaissance Dam on Egypt"

[8] Fao, (1971) "Irrigation and Drainage Paper 7, Rome"

[9] Fao, (2017) "Water Use Efficiency" Thematic Workshop Theme 2:

[10] Forkutsa, I., Sommer, R., Shirokova, Y., Lamers, J., Kienzler, K., Tischbein, B., Martius, C. and Vlek, P., (2009) "Modeling irrigated cotton with shallow groundwater in the Aral Sea Basin of Uzbekistan: I. Water dynamics" Irrigation Science 27:4 331-346

[11] Guswa, A. J., Celia, M. A. and Rodriguez-Iturbe, I., (2002) "Models of soil moisture dynamics in ecohydrology: A comparative study" Water Resources Research 38:9 5-1-515

[12] Hsu, C. and Sandford, B., (2007) "The Delphi technique: making sense of consensus" Practical assessment, research \& evaluation 12:10 1-8

[13] Ibrakhimov, M., Martius, C., Lamers, J. and Tischbein, B., (2011) "The dynamics of groundwater table and salinity over 17 years in Khorezm" Agricultural Water Management 101:1 52-61

[14] Ikramov, R. K., (2004) "Principles of Water and Salt Management in the Irrigated Areas of the Central Asia in Conditions of Water Scarcity. Gidroingeo, Tashkent" 192

[15] Il'ichev, A. T., Tsypkin, G. G., Pritchard, D. and Richardson, C. N., (2008) "Instability of the salinity profile during the evaporation of saline groundwater" Journal of Fluid Mechanics 614:87-104

[16] Kahlown, M. and Ashraf, M., (2005) "Effect of shallow groundwater table on crop water requirements and crop yields" Agricultural Water Management 76:1 24-35

[17] Katschnig, D., Broekman, R. and Rozema, J., (2013) "Salt tolerance in the halophyte Salicornia dolichostachya Moss: growth, morphology and physiology" Environmental and Experimental Botany 92:32-42

[18] Kiseliova, I. and Jumaniyazov, A., (1975) "To the question about optimal groundwater regime. SoyuzNIHI series: questions of amelioration and irrigation during cotton production. Tashkent, Uzbekistan"

[19] Kurbanbaev and K., (2006) "The choice of optimal ameliorative regimes and drainage 
[20] parameters for conditions of Karakalpakstan" Conference Proceedings, SANIIRI (Central-Asian Research Institute of Irrigation Science named after Jurin), Tashkent, Uzbekistan 223-230

[21] Maas, E., (1984) "Crop tolerance" California Agriculture 38:10 20-21

[22] Munns, R., Husain, S., Rivelli, A. R., James, R. A., Condon, A. G. T., Lindsay, M. P., Lagudah, E. S., Schachtman, D. P. and Hare, R. A., (2002) "Avenues for increasing salt tolerance of crops, and the role of physiologically based selection traits" Progress in Plant Nutrition: Plenary Lectures of the XIV International Plant Nutrition Colloquium 247:93105

[23] Neave, M. and Rayburg, S., (2006) "Salinity and erosion: a preliminary investigation of soil erosion on a salinized hillslope" IAHS PUBLICATION 306:531

[24] Niu, G., Rodriguez, D., Mendoza, M., Jifon, J. and Ganjegunte, G., (2012) "Responses of Jatropha curcas to salt and drought stresses" International journal of agronomy 2012:

[25] Novikova, A. V., Ladnykh, V. Y. and Krivonosova, G. M., (1981) "Recommendations for soil leaching treatment with the use of prinkler irrigation together with other techniques for esalinization and improvement of salt-affected soils within the Krasnoznamenskaya Irrigation System."

[26] O'loughlin, J., Mcdonnell, K. and Finnan, J., (2017) "Establishing miscanthus x giganteus crops in Ireland through nodal propagation by harvesting stems in autumn and sowing them immediately into a field" Biomass and bioenergy 107:345-352 http://dx.doi.org/10.1016/j.biombioe.2017.08.010

[27] Ospmi, (2007) "Office of Statewide Project Management Improvement, Project Risk Management Handbook, Second Edition"

[28] Pessarakli, M., (1994) "Handbook of plant and crop stress"

[29] Pessarakli, M., (2016) "Handbook of plant and crop stress"

[30] Pitman, M. G. and Läuchli, A., (2002) "Global impact of salinity and agricultural ecosystems" Salinity: environment-plants-molecules 3-20

[31] Qadir, M., Quillérou, E., Nangia, V., Murtaza, G., Singh, M., Thomas, R. J., Drechsel, P. and Noble, A. D., (2014) "Economics of salt-induced land degradation and restoration" Natural Resources Forum 38:4 282-295

[32] Ragab, A. a. M., (2000) "Physical properties of some Egyptian soils. Ph.D. Thesis, Fac. of Agric. Cairo Univ., Egypt."

[33] Safdar, H., Amin, A., Shafiq, Y., Ali, A., Yasin, R., Shoukat, A., Hussan, M. U. and Sarwar, M. I., (2019) "A review: impact of salinity on plant growth" 17:1 34-40

[34] Shahid, S. A., (2013) "Irrigation-Induced Soil Salinity Under Different Irrigation Systems-Assessment and Management: Short Technical Note" Clim Chang Outlook Adapt: Int J 1:1 19-24

[35] Shannon, M., Banuelos, G., Draper, J., Ajwa, H., Jordahl, J. and Licht, L., (1999) "Tolerance of hybrid poplar (Populus) trees irrigated with varied levels of salt, selenium, and boron" International Journal of Phytoremediation 1:3 273-288

[36] Sinclair, T. R., Tanner, C. B. and Bennett, J. M., (1984) "Water-use efficiency in crop production" Bioscience 34:1 36-40

[37] Soylu, M., Kucharik, C. J. and Loheide Ii, S. P., (2014) "Influence of groundwater on plant water use and productivity: development of an integrated ecosystem-variably saturated soil water flow model" Agricultural and forest meteorology 189:198-210

[38] Thimmappa, K., Singh, Y., Raju, R., Kumar, S., Tripathi, R. S., Pal, G. and Reddy, A. A., (2015) "Reducing farm income losses through land reclamation: a case study from IndoGangetic plains" 
[39] U.S.Salinity.Laboratory.Staff, (1954) "Diagnosis and Improvement of Saline and Alkali Soils. In: USDA Agric Handbook No. 60. U.S Government Printing Office, Washington, D.C."

[40] Vargas, R., Pankova, E. I., Balyuk, S. A., Krasilnikov, P. V. and Khasankhanova, G. M., (2018) "Handbook for saline soil management"

[41] Wilcox, L. V., (1955) "Classification and use of irrigation waters" 969:

[42] Xia, J., Zhang, S., Zhao, X., Liu, J. and Chen, Y., (2016) "Effects of different groundwater depths on the distribution characteristics of soil-Tamarix water contents and salinity under saline mineralization conditions" Catena 142:166-176

[43] Yadav, P., Priyanka, P., Kumar, D., Yadav, A. and Yadav, K., (2019) "Bioenergy Crops: Recent Advances and Future Outlook" Prospects of Renewable Bioprocessing in Future Energy Systems 315-335 